\title{
A BIOPOLÍTICA E OS CONTORNOS DA CIDADE: UMA ANÁLISE DOS MECANISMOS DE GERENCIAMENTO A PARTIR DE MICHEL FOUCAULT
}

\author{
Luana Marina dos Santos" \\ Gerson Neves Pinto**
}

Resumo: Partindo do método hipotético-dedutivo, esta pesquisa objetiva identificar em que medida a biopolítica se apresenta como um mecanismo de gerenciamento no que diz respeito à compreensão dinâmica e funcional das cidades. A hipótese sugere que a dinâmica biopolítica das cidades é protagonizada pela exclusão e eliminação de determinados sujeitos dos centros urbanos, além de não prezar pela salvaguarda de determinados direitos e garantias a estes indivíduos. Os resultados da pesquisa apontam que o Estado logra êxito em instituir mecanismos de controle aptos a privar determinados grupos de exercerem plenamente seus direitos outrora garantidos a partir do controle geográfico das cidades.

Palavras-chave: Biopolítica; Racismo; Cidade; Poder; Direitos e garantias fundamentais.

\section{BIOPOLITICS AND THE CITY OUTLINES: AN ANALYSIS OF MANAGEMENT MECHANISMS FROM MICHEL FOUCAULT}

\begin{abstract}
Based on the hypothetical-deductive method, this research aims to identify how the biopolitics presents itself as a mechanism with regard to the dynamic and functional understanding of cities. The hypothesis suggests that the biopolitical dynamics of cities are characterized by the exclusion and elimination of certain subjects from urban centers, in addition to not cherishing the safeguarding of certain rights and guarantees to these individuals. The results of the research show that the State is successful in establishing control mechanisms able to deprive certain groups of fully exercising their rights that were once guaranteed by the geographic control of cities.
\end{abstract}

Keywords: Biopolitics; Racism; City; Power; Fundamental rights and guarantees.

\section{INTRODUÇÃO}

A biopolítica, considerada uma estratégia de poder que abrange a gestão da vida humana e as considerações do ser humano enquanto espécie e indivíduo, configura-se como um elemento-chave apto a atravessar as ponderações estatais sobre a tomada de decisões soberanas e formulações de estratégias políticas. A partir da perspectiva focaultiana do

\footnotetext{
* Mestranda em Direito Público pela Universidade do Vale do Rio dos Sinos. Graduada em Direito pela mesma universidade. Bolsista CAPES/PROEX. E-mail: luanamarinads@gmail.com.

** Doutor em Filosofia pela Ecole Pratique Des Hautes Etudes, França. Professor no programa de pós graduação na Universidade do Vale do Rio dos Sinos. E-mail: gerson.p@terra.com.br
} 
instituo da biopolítica, a vida natural dos seres humanos se tornou um fator decisório na atuação do poder estatal, que atenta-se não somente à vida em si, mas a todos os processos que lhe são referentes, como: mortalidade, saúde, natalidade, raça e etc. Essas considerações permitem observar que o contexto biopolítico, enquanto ferramenta de gestão da vida humana, perpetua-se, estabelecendo formas de controle social que incluem ou excluem sujeitos do meio social e político.

Os mecanismos dessa gestão operam sob um modelo de sociedade regido pelo capitalismo, em que os critérios para a regulamentação do comportamento humano se concentram em acelerar o desenvolvimento do sistema vigente. Para Foucault, nesse sentido, a construção social e política que recai sobre as raças apresentam-se como formas úteis de fragmentar e permitir ao poder subdividir a espécie humana, proporcionando, dessa forma, a segregação de determinada parcela da população. Isso abre espaço, também, para condutas estatais racistas, que se manifestam com a intensificação da segregação de certos indivíduos dos espaços urbanos que, de certa forma, não atendem aos padrões normativos e sociais.

A cidade, quando situada neste contorno biopolítico, se apresenta segmentada, encobrindo sujeitos e desacortinando, cada vez mais, a atual crise sistêmica, responsável por fortalecer um sistema que não procura salvaguardar a vida humana de maneira homogênea. Diante disso, o objetivo central da pesquisa se concentra em demonstrar em que medida a biopolítica -perspectiva filosófica cunhada pelo filósofo francês Michel Foucault- se apresenta como um mecanismo de gerenciamento no que diz respeito à compreensão dinâmica e funcional das cidades, protagonizada pela exclusão e eliminação de determinados sujeitos dos centros urbanos, a partir da não salvaguarda de determinados direitos e garantias.

Para tanto, a partir do método hipotético-dedutivo, aliado ao levantamento bibliográfico e documental, far-se-á, no primeiro capítulo, a partir da concepção do poder, em Hobbes, uma análise acerca do instituto da biopolítica, observando os aportes necessários para compreender de que maneira este instituto se apresenta como ferramenta útil à compreensão do gerenciamento humano da vida humana pelo Estado. Posteriormente, objetivar-se-á analisar, brevemente, de que maneira esta forma de controle protagoniza a não salvaguarda de direitos e garantias fundamentais em prol de determinadas camadas sociais, especialmente aquelas localizadas fora dos centros urbanos. Por fim, identificar-se-á, a partir da análise do racismo institucional em Michel Foucault, de que maneira os mecanismos desta gestão logram êxito em operar sob um modelo de sociedade onde os critérios para a regulamentação 
do comportamento humano se concentram em segmentar e permitir ao poder subdividir a espécie humana por meio do encobrimento de sujeitos, proporcionando, dessa forma, a exclusão de parcela da população que é esquecida pelos poderes públicos.

A hipótese sugere que a dinâmica biopolítica das cidades é protagonizada pela exclusão e eliminação de determinados sujeitos dos centros urbanos, além de não prezar pela salvaguarda de determinados direitos e garantias a estes indivíduos. Os resultados da pesquisa realizada apontam que, através da dimensão biopolítica, o Estado logra êxito em instituir mecanismos de controle que se tornam aptos a privar determinados grupos de exercerem plenamente seus direitos outrora garantidos a partir do controle geográfico das cidades.

Impende salientar que a presente pesquisa não pressupõe o esgotamento do tema, tampouco sugere uma resposta conclusiva ao objeto que aqui se apresenta, mas sim, propõe apresentar questões que possam contribuir para a compreensão de um mecanismo de controle que se utiliza da gestão dos corpos para construir estados de dominação, onde determinados indivíduos acabam sendo colocados à margem ou excluídos da vida em sociedade.

\section{A BIOPOLÍTICA EM MICHEL FOUCAULT}

De acordo com Hobbes (1988), o poder e a instituição política constituem-se em uma convenção ou um pacto. É, pois, pela questão do pacto, que devemos dar início à compreensão sobre o que é o poder. Para Hobbes, esta compreensão pressupõe, também, um questionamento aberto sobre a estrutura interna do próprio poder. Para isso, é necessário começar pela convenção social -constituída como ato "proto-fundador"-, isto é, uma fundação originária. Para Hobbes, o Estado se apresenta como "proto-fundador" responsável pela condição política de todas as outras instituições. Ou seja: não podem haver instituições préestatais, uma vez que todas as instituições resultam da própria instituição política. (HOBBES, 1988).

Deste modo, compreende-se que a definição de Hobbes (1988), no que diz respeito à justiça, quando concebida como respeito aos acordos passados, é inovadora. Conforme o capítulo XV, do Leviatã (1988), para Hobbes, na definição apresentada como "fonte e a origem da justiça”, é necessário “[...] que os homens cumpram seus acordos, uma vez que eles foram estabelecidos". Afinal, se os homens não mais dispõem de um critério objetivo de bem para orientar suas ações, então como é possível que eles concordem sobre o que são as leis morais 
e, inclusive, a própria a justiça? Ainda que as teorias clássicas da lei natural possam deduzir uma concepção substancial da justiça de uma concepção objetiva do bem - por exemplo, uma concepção superior da vida boa -, essa possibilidade não mais se apresenta para Hobbes e seus sucessores.

A razão para isso, encontra-se prevista na nova teoria moral criada por Hobbes, na medida em que repousa sobre uma nova concepção do bem. Isso porque, “ [...] o objeto, qualquer que ele seja, do apetite ou do desejo de um homem, é isso que esse chama de bom. E ele chama de mau o objeto de seu ódio ou aversão; vil e negligenciável, o objeto de seu desdenho”. (HOBBES, 1988, p. 58). Esclarece, portanto, que esta inovação conceitual logra êxito em transformar profundamente o pensamento moral na medida em que o desejo não mais é visto como o meio para alcançar um bem definido independentemente dele, mas como o princípio em função do qual uma coisa será, ou não, boa para os indivíduos. Segue-se, logicamente, que o "bem" não mais reside na "natureza dos objetos em si”, mas, sim, no juízo das pessoas que os desejam.

Segundo John Finnis, a origem desta mudança encontra-se no início do séc. XVII, especialmente a partir do pensamento de Hobbes, ao estabelecer o contraste ente a lei (Lex) e os direitos (Jus). Este, por sua vez, afirma que a lei é uma restrição à liberdade, justificando-a em nome da segurança:

Jus e lex, o direito e a lei, é necessário distingui-los um do outro. Pois o direito consiste na liberdade de fazer ou de omitir, ao passo que a lei determina ou obriga a uma dessas duas coisas. De modo que a lei e o direito se distinguem tanto como a obrigação e a liberdade, as quais são incompatíveis quando se referem à mesma matéria. (HOBBES, 1988, p. 113).

Esclarece-se, desta forma, que o direito se identifica com a liberdade individual, ao mesmo tempo em que se contrapõe à lei, como algo anterior à esta e que, está consequentemente, limitado por ela. Nesse sentido, Hobbes (1988) sustenta que um homem possui o máximo de direitos quando se encontra no "estado de natureza", isto é, na ausência da lei, pois "numa tal condição todo homem tem direito a todas as coisas, incluindo os corpos dos outros." (FINNIS, 1980, p. 208).

Talvez, para que haja maior compreensão acerca da questão do conflito entre o bem individual e o bem comum, deva-se examinar a concepção moderna de "bem", tida como uma “inovação conceitual” em que Hobbes protagoniza uma grande transformação para a filosofia moral. Conforme Luc Foisneau (2009), comentador contemporâneo de Hobbes, “[...] segue-se 
logicamente que o 'bem' não mais reside na 'natureza dos objetos em si', mas no juízo das pessoas que o desejam". Isso quer dizer, existe uma mudança subjetivista na filosofia moral em Hobbes, uma vez que, agora, cada homem, segundo suas sensações e sua imaginação, definirá o que é bom para si. Ou seja: não é mais o objeto, o que detém ou determina o significado do bem, mas o próprio homem.

Deste modo, Hobbes (1988, p. 58) reconhece a força do desejo no homem, o medo, a cobiça e o ódio, pois “[...] seja qual for o objeto do apetite ou desejo de qualquer homem, esse objeto é aquele que cada um chama bom; ao objeto de seu ódio e aversão chama mau, e ao que seu desprezo chama vil ou indigno". Neste ínterim, verifica-se que a visão hobbesiana é pessimista: o desejo está mais do lado da destruição dos outros do que do amor aos outros, razão pela qual, no tocante à sociedade, seu bom funcionamento não pode ser garantido exceto por uma instancia transcendente, sempre capaz de abusar de seu poder. (HOBBES, 1988).

Assim, se, de acordo com Hobbes, o contrato social se materializou como uma estratégia que teve por finalidade oferecer segurança e, assim, proteger os indivíduos "diante dos perigos da morte violenta", configurando-se como um "recurso filosófico e jurídico para justificar a centralidade do poder nas mãos de uma única entidade", pode-se dizer que a vida, exercida sob o poder absoluto do soberano, é constitutiva do elemento da ordem em sociedade. (NASCIMENTO, 2012, p. 156).

Em prol de uma garantia, simetria e regularidade da ordem social, o soberano passa a representar, em figura única, aquele que primordialmente detém a responsabilidade sobre a vida. O contrato social, nesse sentido, pode ser entendido como aquele a partir do qual os indivíduos optam por atribuir a um único detentor de poder a tarefa de reorganizar a vida em sociedade, exceto, no entanto, desconsiderar os meios de sobrevivência humana. (NASCIMENTO, 2012).

Para Nascimento (2012), isso é o que traduz o início de um novo regime societário estrutural, já que a modernidade inaugura uma estrutura de dominação na qual o poder se instrumentaliza e passa às mãos do soberano. Este, por sua vez, passa a fazer uso legítimo do poder para assegurar o direito dos homens a segurança da própria vida.

Sob uma ótica crítica à noção contratualista embasada por Hobbes, Nascimento (2012, p. 157) sustenta que a atribuição conferida ao soberano quanto à proteção da vida humana abarca um fator decisivo para a produção da dominação de determinados grupos 
sociais sobre outros, visto que "em nome da vida, o homem foi submetido a um processo de seleção segundo o julgamento do que é indesejável e imprestável aos olhos do soberano". Isso porque, na perspectiva da autora, a igualdade não se constitui como uma característica natural dos indivíduos, e sim como um fator socialmente construído, como o resultado de uma organização social. Nesse sentido, a conferência de direitos igualitários de forma recíproca é o que indica o traço originário social da igualdade, e não a sua dimensão "natural". (NASCIMENTO, 2012).

Neste sentido, Hanna Arendt (1984) criou uma ponte para compreender como se justificam os atos totalitários do soberano. Para Hanna, quando a população se encontra inserida em um contexto pautado pela dominação dos povos e da supremacia dos poderes concentrados em um só, o soberano encontra pretextos para praticar determinado processo de seleção imbuído em conceitos próprios. Sobre o tema, esclarece Nascimento (2012, p. 156) que,

contrária à tradição contratualista, que fundamenta juridicamente o acordo coletivo de transferência do poder natural dos homens em troca de proteção da vida, considerando por isso a igualdade como fenômeno natural, Arendt nega qualquer forma de alienação do poder e naturalização da igualdade. Eleger a vida como fundamento da política é atribuir ao poder a mesma estrutura mecânica e repetitiva do processo biológico; e foi dessa forma que se passou a justificar a equação da política com a violência.

Desta forma, o contrato social, ao pressupor que o indivíduo abra mão de poderes naturais em prol de garantias asseguradas e constituídas pelo soberano, passa, conforme Hanna Arendt (1984), a pertencer a um conjunto de relações jurídicas e econômicas. Esse indivíduo político, ao se condicionar ao poder superior, acaba por dar ênfase a uma condição permanente de guerra a fim de assegurar a ordenação social destes mesmos indivíduos, contrariando, desta forma, a própria condição da pluralidade humana. (ARENDT, 1984).

Ocorre que, neste aspecto, nada teriam os homens que os diferenciassem uns dos outros, tornando-os uma massa não identificável. Com efeito, "a perda da liberdade em troca de segurança significou a criação de condições justificáveis à prática da violência pelo Estado.” (NASCIMENTO, 2012, p. 158). Entender a inserção do homem como centro da vida política, tornar-se-ia fundamental para que os indivíduos pudessem exercer o direito de lutar por expressar suas singularidades "como expressão de uma diversidade comunicável" 
(NASCIMENTO, 2012, p. 158), para, finalmente, identificar o próprio indivíduo como fonte geradora de poder.

O dilema traçado por Arendt (1984) viabiliza o entendimento de Michel Foucault (2008), que, em seu projeto filosófico, procurou entrelaçar ${ }^{1}$ com a história da modernidade mutações que acarretam transformações políticas, disseminando, desta forma, a tomada de poder sobre o homem vivo - desde a perspectiva individual (disciplina do corpo) até a perspectiva de massa (controle da população). Na percepção de Foucault (2012), o limiar de modernidade biológica de uma sociedade está no momento em que o homem entra em jogo no estratagema político de um Estado. Segundo o autor (2012, p. 134),

o homem, durante muito tempo, permaneceu o que era para Aristóteles: um animal vivo e, além disso, capaz de existência política; o homem moderno é um animal, em cuja política, sua vida de ser vivo está em questão.

Nesta senda, Foucault (1986) utiliza-se do termo biopolítica para designar um estágio de poder que é posterior às práticas disciplinares ${ }^{2}$, utilizadas para governar o indivíduo no estágio incipiente do capitalismo - quando se fazia necessária a produção de "corpos dóceis" por meio de instituições como a escola, o hospital, a fábrica e a prisão - e que agora passa a ser considerado como a prática de biopoderes locais. Com o instituto da biopolítica, que, para Foucault, representa a forma como poder tende a se transformar no alvorecer do século XIX, os alvos do exercício do poder do Estado passam não mais a ser orientados pela individualização dos corpos, mas sim, "a ser os efeitos e processos gerados pela vida em conjunto". (AYUB, 2015, p. 68).

A biopolítica, conforme ensina Foucault (2010), desacortina relações de poder que não mais se alicerçam sobre os corpos individuais, mas sim, sobre os corpos-espécie. Isso porque, para o filósofo, a biopolítica protagoniza um estágio de poder que logra êxito em gerenciar não somente os corpos de uma sociedade, mas sim, a própria vida destes indivíduos,

\footnotetext{
${ }^{1} \mathrm{O}$ pensamento de Hobbes, segundo Foucault, concentra de maneira clara os três princípios da teoria da soberania : o sujeito, a unidade do poder e a lei: "Dito de outro modo, a teoria da soberania, é o ciclo do sujeito ao sujeito, o ciclo do poder e dos poderes, o ciclo da legitimidade e da lei [...]. A teoria da soberania pressupõe o sujeito; ela visa fundar a unidade essencial do poder e ela se desdobra sempre no elemento a priori da lei. Temos assim, um Triplo primitivismo: do sujeito a ser submetido, da unidade do poder de fundar e da legimidade a respeitar. Sujeito, unidade do poder da lei: eis, eu creio, os elementos entre os quais se desenvolve a teoria da soberania, a qual ao mesmo tempo se dá e procura fundá-los". (FOUCAULT, 2010, p. 38).

$2 \mathrm{Na}$ acepção instituída pelo autor, a noção de disciplina tangencia a necessidade de práticas disciplinares que conduzam os indivíduos, a partir do trabalho de seus corpos, a produzirem, cada vez mais, tempo e trabalho a serviço da produção capitalista. Esta submissão disciplinar acaba por assumir uma forma de governo que impera sob os indivíduos de forma individual e repetitiva, como se o poder do estado pudesse tornar o indivíduo homogêneo e massificado. (WERMUTH; SANTOS, 2016).
} 
de maneira planificada. A biopolítica, neste sentido, se encontra concentrada na vida enquanto fenômeno, porquanto configura-se como um elemento-chave apto a atravessar as ponderações estatais sobre a tomada de decisões soberanas e formulações de estratégias políticas, atuando como um instrumento de gerenciamento de corpos, de maneira abrangente. (FOUCAULT, 2010).

Com a instituição da biopolítica, de acordo com Michel Foucault (2010), o Estado procura a utilização de mecanismos que busquem normalizar e regulamentar a população, a fim de aumentar a sua produtividade. Assim, tendo em vista que os mecanismos dessa gestão operam sob um modelo de sociedade regido pelo capitalismo, em que os critérios para a regulamentação do comportamento humano se concentram em acelerar o desenvolvimento do sistema vigente, a construção social e política que recai sobre as raças, apresentar-se-ia como forma útil de fragmentar e permitir ao poder subdividir a espécie humana, proporcionando, dessa forma, a exclusão de parcela da população que é esquecida pelos poderes públicos. (FOUCAULT, 2010).

Com a inserção do fragmento do campo biológico como instrumento estratégico das estruturas da biopolítica, elementos como o racismo e a exclusão de certos indivíduos da vida em sociedade, se configuraram como uma espécie de "limpeza social", onde o poder estabeleceu a possibilidade de exclusão estrutural daqueles grupos que não lograram êxito em acompanhar o modo de produção e o consumo desenfreado pelo acúmulo econômico. (FOUCAULT, 2010).

Pelbart (2003) alicerça este entendimento, afirmando que esta mesma fragmentação só foi possível em razão da proliferação de condutas que se alicerçaram por meio da segregação de grupos sociais que não atendem aos padrões normativos e sociais impostos pela gestão biopolítica do Estado. Entre estes mecanismos, estaria o racismo, que, nesta esfera, compreende-se, de acordo com Foucault, como um direito de eliminação. Este, por sua vez, se perfectibiliza por meio de diversos segmentos, inclusive por meio da seletividade da população carcerária ${ }^{3}$, alicerçando, desta forma, a compreensão de que o racismo estrutural fomenta a exclusão daqueles grupos que, para o sistema de gerência biopolítico, não se incluem no modelo de sociedade esperado. (FOUCAULT, 1977).

\footnotetext{
${ }^{3}$ Conforme dados, a maioria da população carcerária é representada, majoritariamente, pela população negra. Para mais informações acerca da porcentagem da população negra no sistema carcerário, acesse: https://www2.camara.leg.br/atividade-legislativa/comissoes/comissoes-permanentes/cdhm/noticias/sistemacarcerario-brasileiro-negros-e-pobres-na-prisao.
} 
Nesta perspectiva, percebe-se que o sistema de produção imposto pelo sistema biopolítico, conforme explicado por Foucault, tem como um de seus objetivos segregar e estigmatizar grupos que não se enquadram em um modelo social específico, repercutindo, assim, na configuração de um sistema carcerário composto por indivíduos vulnerabilizados e marginalizados do contexto social, principalmente por aqueles advindos das camadas hipossuficientes da população, que, em sua grande maioria, são negros ${ }^{4}$. Com efeito, é possível compreender que a biopolítica, mediante controles de dominação que procuram, insistentemente, instaurar uma manutenção de vigilância acerca dos afazeres do homem, acaba refletindo e atuando de forma contrária à própria vida.

A forma de controle biopolítico, para Foucault (2010), se traduz como uma forma legítima de dominação, onde o controle social se torna um mecanismo de poder capaz de criminalizar indivíduos considerados inservíveis e impossíveis de serem enquadrados na forma de produção vigente. É, neste contexto, que gestão biolítica, alijada por Foucault, contribui para a compreensão de um mecanismo de controle que se utiliza na gestão dos corpos para construir estados de dominação, onde determinados indivíduos acabam sendo colocados à margem ou excluídos da vida em sociedade.

\section{BIOPOLÍTICA E A REGULAMENTAÇÃO DA VIDA NA CIDADE}

Conforme abarcado brevemente no capítulo anterior, a biopolítica desacortina relações de poder pautadas no gerenciamento dos indivíduos, substancialmente, nos processos atinentes à vida em conjunto em determinada sociedade. Assim, considerando que, para Foucault (2008), na modernidade, a vida começa a ser considerada produtiva e útil pelo poder $^{5}$, a política passaria, então, consequentemente, a governar os corpos e regulamentar a própria vida, isso é: “deixar morrer ou fazer viver", já que o poder moderno, segundo Foucault, “desconhece a morte".

\footnotetext{
${ }^{4}$ Para saber mais sobre a porcentagem da população negra nas camadas hipossuficientes do Brasil, acesse: https://www.metropoles.com/brasil/porcentagem-de-negros-na-pobreza-e-miseria-dobrou-em-5-anos-no-brasil . ${ }^{5} \mathrm{O}$ conceito de poder utilizado neste estudo é o cunhado por Foucault. O poder é tratado como uma intersecção, que se incumbiu tanto do corpo quanto da vida em geral, consolidada através de simples atos reiterados no próprio cotidiano dos indivíduos. Intercedido à biopolítica, o poder materializa-se mediante a atuação do biopoder, através de biopoderes locais, que fragmentam e censuram o processo biológico dos seres, exercido mediante centros de transmissão que se conectam e circulam dentro do próprio seio da população. Não se trata, portanto, de um poder estagnado, que apenas cria e recria através de comandos de uma única lei e/ou ser, mas de um poder que circula e transmuta de forma reiterada, a partir de métodos fragmentados e espalhados por todos os campos da vida humana. (FOUCAULT, 1986).
} 
Assim, de acordo com o filósofo, o fenômeno biopolítico passa a transcender a barreira instituída pela soberania. Não se trata mais, portanto, daquele poder soberano que detém o domínio sobre a morte e a vida do indivíduo, mas, sim, sobre uma intersecção do poder que gera a vida, o "fazer" viver. Desta maneira, de acordo com Foucault, é possível dizer que a política moderna protagoniza o gerenciamento da vida humana. A biopolítica, caracterizar-se-ia, portanto, acerca da premissa do "fazer viver" e "deixar morrer". Ou seja, uma prática política que objetiva otimizar a vida humana por meio de gerenciamentos específicos. No entanto, sobre este ponto, é importante consignar que, por "deixar morrer", não se compreende, na perspectiva foucaultiana, unicamente o assassínio direto, mas também, e substancialmente, tudo aquilo que pode ser considerado assassínio indireto: "o fato de expor à morte, de multiplicar para alguns o risco de morte ou, pura e simplesmente, a morte política, a expulsão, a rejeição ${ }^{6 \%}$. (FOUCAULT, 2010, p. 216).

Para Foucault (2008), as relações hierárquicas de poder do Estado se utilizam, principalmente, das próprias táticas de poder do próprio ser. Desta forma, a vida, que agora representa a multiplicidade de humanos (população), passou a se sobrepor à técnica de controle dos indivíduos pelas formas de disciplina, vigilância e normalização, focadas essencialmente nos seus corpos individuais, dando ênfase, agora, a uma forma de política que objetiva o agrupamento de seres que formam uma massa global, afetada por processos de conjunto. (BITTENCOURT, 2010).

Pelbart (2003), ao comentar a biopolítica em Foucault, alicerça o entendimento de que o Estado, por vezes, em razão desta necessidade de controle, que objetiva principalmente normalizar uma população na busca de otimizar a sua produtividade, acaba aplicando um controle desmedido, que aliena o indivíduo da cena política e não lhe assegura direitos fundamentais. Neste mesmo sentido aparece o entendimento de Foucault (2010), que explica que, ainda que o estado biopolítico reúna dispositivos de segurança que procurem "fazer viver", o problema de morte permanece aberto na medida em que este mesmo Estado trabalha para produzir mecanismos que permitam a morte de uma parcela seletiva da população em prol da segurança e da manutenção de "classes superiores". (FOUCAULT, 2010).

\footnotetext{
${ }^{6}$ De acordo com Bazzicalupo (2017, p. 50), o dispositivo racista passa a ser estendido da ação direta e efetiva de tirar a vida para o ato de expor à morte, de modo que "a normalização de emergência e de exceção multiplica o risco de morte para determinados grupos da população".
} 
Nesse sentido, considerando que a biopolítica também representa uma busca pela normalização dos corpos, a partir de dispositivos de vigilância, tanto de âmbito particular, quanto de âmbito público, é possível abrir espaço para uma reflexão sobre a biopolítica do espaço urbano "uma vez que a função desses diversos dispositivos se torna, sobretudo, a de proteger excluindo, proteger normalizando, instaurando, pois, uma polarização social". (ALANI, 2019, p. 447).

Lara \& Butturi Jr (2018, p. 652), salientam a forma que a biopolítica, procedida de elementos de controle, adentra o espaço urbano e o modifica. Pois, "antes de ser uma política de sujeitos, a biopolítica tornou-se uma política populacional, que mede e regula, constrói e produz comunidades humanas através de programas de mortalidade e planejamento familiar, regras de higiene e controle de fluxos migratórios”. Do ponto de vista teórico, então,

as categorias de biopolítica e biopoder tentam dar conta da normalização biológica da espécie humana e conduziram, desde Foucault, à problemática da governamentalidade, tendo em vista os enunciados sobre a segurança e o risco. (LARA \& BUTTURI JR, 2018, p. 653)

Considerando, portanto, que o gerenciamento da biopolítico objetiva especificar critérios para definir o que pode ser incluído e excluído da vida em sociedade - em prol de uma sociedade mais "limpa", organizada e produtiva - (FOUCAULT, 2008), é possível que este mesmo gerenciamento, "ao mesmo tempo em que visa proteger os corpos de parte da população produtiva ou rentável para a cidade, é também capaz de excluir outra parcela". Assim, o Estado, "ao definir critérios sobre o que é excluído e incluído, pode também aplicálos no disciplinamento dos corpos no espaço, fazendo do poder um exercício ambivalente de expressão ou exercício da biopolítica, uma vez que ele pode tanto 'agregar' ou 'expulsar' os marginalizados". (ALANI, 2019, p. 448).

Assim, compreende-se que os dispositivos de controle provenientes da biopolítica, ao atuarem nos processos biológicos da população em conjunto, também podem, por consequência, empregar dispositivos de controle nos espaços urbanos -ruas, lojas, moradias, centros e periferias-, porquanto a construção arquitetônica e a ocupação destes espaços também se apresentam necessários para garantir o funcionamento do Estado sobre os corpos. Neste mesmo sentido, explica Ritter (2014), ao afirmar que a própria segurança dos espaços urbanos se coaduna com a gestão biopolítica, uma vez que esta possibilita, ao mesmo tempo, a proteção de indivíduos e a consolidação de abuso de poderes locais. 
Como já mencionado, a biopolítica procura gerenciar a liberdade dos espaços, na medida em que objetiva que as pessoas possam atingir maior eficiência, uma vez que este instituto, ao ter a vida como objeto, não se preocupa somente em destruir a vida inútil, mas, como já exposto, tornar produtiva a vida útil. Assim, considerando que o sistema de gestão biopolítico objetiva planejar o uso comum dos espaços urbanos com o intuito de consolidar os propósitos destinados a este planejamento estrutural, verifica-se que os mecanismos desta gestão implicam em filtrar os corpos circuláveis em determinados ambientes. Logo, é possível compreender, também, de acordo com Foucault, que determinados sujeitos não são necessariamente reconhecíveis como indivíduos que "merecem" a vida e a salvaguarda de direitos e garantias de maneira igualitária a todos aqueles que convivem em uma mesma sociedade. (RITTER, 2014).

De acordo com a pesquisa elaborada por Alani (2019, p. 449), esta produtividade não transparece somente a partir de meios diretos de consumo, mas sim, e substancialmente, pelo aumento de locais de descanso em espaços onde haja vidas que 'importam'. Desta forma, "espaços como ciclovias, academias ao ar livre, gramados e parques, parecem ser orientados àqueles que merecem viver, e viver mais". Em outras palavras, "a biopolítica trata o cuidado da vida humana como princípio formal da política moderna, cuidando dela quando útil e a abandonando quando inútil”. (RITTER, 2014, p. 127).

Os meios de estratégia biopolítica podem incluir, inclusive, situações simples, como, por exemplo: os processos de iluminações das vias públicas e a numeração das casas e edificações. Estes processos objetivam organizar e, consequentemente, auxiliar na circulação dos corpos em determinado espaço comum. No entanto, é importante observar que, tais estratégias, ao mesmo tempo que visam buscar a proteção de determinados corpos, também expõem e afastam determinados sujeitos de locais selecionados, buscando purificar ambientes. Assim, “[...] diante da relação da vida com o poder na biopolítica, há o cuidado com a vida humana e, ali, dentro desse cuidado, está sempre o controle da circulação dentro de espaços". (ALANI, 2019, p. 452).

Agamben (2010, p. 184) explica que o povo constitui tudo "aquilo que não pode ser incluído no todo do qual faz parte, e não pode pertencer ao conjunto no qual já está desde sempre incluído". É, neste sentido, que se imperam as contradições provenientes do próprio governo biopolítico, ou seja: ao mesmo tempo que a gestão governamental passa a priorizar a vida humana, ela o faz por meio da "exclusão, da língua, do sangue e do território". Permite- 
se, assim, certa abertura para a perpetuação de um processo de higienista que permeia os espaços urbanos em sua configuração, expulsando determinados corpos daquela ambientação em prol de uma parcela seleta de indivíduos.

O paradoxo imposto pelo gerenciamento biopolítico dentro do espaço urbano toma como exemplo a anulação de corpos "matáveis" e, ao mesmo tempo, a consolidação de dispositivos que procuram "fazer viver" os corpos desejáveis, como, por exemplo, a utilização de câmeras, de seguranças e de iluminação que, ao buscar cercear ou afastar o perigo, também buscam capturar os seres. Solidifica-se, aí, o funcionamento da biopolítica: “[...] gerir corpos, em que de um lado, há recrudescimento da violência e, de outro, o acesso aos serviços e aos direitos sociais". (ALANI, 2019, 460).

De acordo com Foucault (2012, p. 130), independente de integrantes da própria comunidade, "são mortos legitimamente aqueles que constituem uma espécie de perigo biológico para os outros". O perigo biológico, aqui instituído por Foucault, é protagonizado por meio das raças, e, inclusive, daqueles que não se adequam ao padrão homogeneizador imposto pelo Estado. Daí que se surgem os movimentos de "limpeza urbana", caracterizados pela desocupação de prédios ${ }^{7}$ e expulsão de pessoas dos centros urbanos. Verifica-se, desta forma, que o "fazer viver", imposto pela biopolítica, ainda que busque a promoção da vida, "não se separa da produção contínua da morte, no interior e no exterior da comunidade entendida como entidade biologicamente homogênea”. (NIELSSON; WERMUTH, 2018, p. 613).

\section{CORTES TANATOPOLÍTICOS E O RACISMO INSTITUCIONAL}

De acordo com Foucault (2008), a cidade seria, a princípio, uma forma de expor, a partir da análise das tecnologias da biopolítica, a correlação entre o governo -como forma de instância política -, e a população como alvo de controle social. Foucault, ainda, explica que a cidade se constitui como um espaço singular no território, submetido à ordem da soberania. Neste mesmo sentido, o filósofo francês explica que o controle das cidades urbanas também sugere a promoção do crescimento do comércio e o desenvolvimento da população, razão pela

\footnotetext{
${ }^{7}$ Exemplo disso, é a ocupação do prédio Lanceiros Negros, em Porto Alegre/RS. A ocupação Lanceiros Negros, criada em 2015, ocupava prédio localizado no encontro das ruas General Câmara e Andrade Neves, de posse do Estado e que estava vazio há mais de uma década no centro histórico de Porto Alegre. A ocupação acabou sendo desfeita pela Brigada Militar em ação com uso de força, no dia 16 de junho de 2017, em razão de uma ação de reintegração de posse determinada pelo Poder Judiciário.
} 
qual o poder do Estado se constitui essencial para promover um arranjo eficaz e convincente, capaz de promover o pleno desenvolvimento das cidades.

Foucault, então,

[...] toma a cidade como manifestação fundamental do poder biopolítico, sugerindo que os dispositivos de segurança funcionariam para criar uma abundância de oportunidades gratuitas e portanto, artificiais, de liberdade, e não exatamente para proporcionar uma melhor condição de vida para os indivíduos, mas para permitirlhes aceitar o poder, produzindo mais e melhor. (LOUREIRO, 2014, p. 59).

Baseado nesta premissa -que protagoniza o exercício de mecanismos que objetivam maior produção da população-, os instrumentos biopolíticos, ao impulsionarem "políticas públicas que fazem viver e criam espaços urbanos de segurança para uma liberdade possível, também fazem, ao mesmo tempo, surgir lugares perdidos, de medo constante e necessidade permanente: "não lugares" de morte" (LOUREIRO, 2014, p. 57). É, justamente aí, que o racismo de estado nas cidades modernas se manifesta: como condição-limite da contínua produção da vida em abundância. Desta maneira, “o bem-estar da população que produz e consome, em sua liberdade e segurança, será tanto mais garantido quando mais violado for o acesso do povo às oportunidades de vida digna na cidade". (LOUREIRO, 2019, p. 59).

Neste compasso, percebe-se que as pessoas inseridas em bairros periféricos, de acordo com os aportes cunhados por Foucault, consolidam o entendimento de que o corte tanatopolítico não possui caráter meramente acidental, porquanto perpetua-se. Trata-se, em verdade, “de um investimento calculado, que cria vida a partir da morte”. É, nestes locais, que uma espécie de estado de exceção ${ }^{8}$ toma espaço, no mesmo ritmo em que a vida e a segurança se articulam no espaço urbano, "amarrando as linhas de força dos fluxos de pessoas e bens e dos processos vitais, na mesma velocidade em que se faz terra arrasada nas comunidades pobres, favelas, cortiços e loteamentos irregulares". (LOUREIRO, 2019, p. 57).

Neste mesmo sentido, conforme alicerça Arend (2018), ainda que os sujeitos, dentro de uma sociedade, sejam considerados pelo Estado como detentores de direitos e garantias fundamentais, sujeitos marginalizados acabam, por consequência de onde vivem, tendo menos direitos do que aqueles que se encontram "bem inseridos à norma do sistema". O espaço

\footnotetext{
${ }^{8}$ Para o filósofo italiano Giorgio Agamben (2010), esta seria uma situação jurídica paradoxal na qual a lei suprime a lei, na medida em que se abolem, por meio da própria lei, certas garantias e direitos individuais e coletivos, expondo os cidadãos ao risco iminente da morte violenta e legalmente justificada.
} 
urbano solidifica este entendimento ao "excluir uma multidão de pessoas dos serviços básicos de cidadania.” (PAESE, 2006, p. 54).

Isso por que,

[...] a partir do momento em que essas populações situadas nas margens da sociedade são reduzidas ao estatuto de "vida nua", elas deixam de ser pensadas como sujeitos de direitos para passarem a ser pensadas exclusivamente como corpos vivos. Assim, enquanto existem sujeitos que não são reconhecidos como cidadãos com direitos e deveres, mas como pura e nua corporeidade, eles podem passar a ocupar esse espaço politicamente perigoso e ambíguo de uma "vida nua". (CAPONI, 2004, p. 453).

O processo biopolítico, pautado pelo racismo de estado e pelo aperfeiçoamento de mecanismos que permeiam locais de exclusão, reflete-se, substancialmente, no cenário urbano brasileiro, porquanto ancorado em processos de desigualdade e preconceito. É, olhando a partir deste prisma, que identificamos, historicamente, nas favelas e periferias, o lugar onde, de modo mais concreto, as pessoas são atingidas pelas violências produzidas a partir de uma lógica racista e classista, cenário este que propicia a não garantia de direitos às populações que ali residem, como a segurança pública, por exemplo.

Não é novidade o aumento da repressão violenta impressa nas favelas do Brasil, especialmente no Rio de Janeiro, por exemplo. Conforme Reportagem de Sousa (2019), somente no primeiro semestre de 2019, "as polícias Militar e Civil mataram mais que o número de homicídios por intervenção de agentes do Estado no período entre 2010 e 2015, segundo dados do ISP (Instituto de Segurança Pública)". Este número estarrecedor revela uma forma de política que, na medida em que permite "que agentes da segurança pública atuem em favelas e periferias sem o respeito aos princípios legais que garantem direitos básicos dessas populações, como a violação de suas casas sem mandado judicial”, não salvaguarda o respeito à certos direitos fundamentais, como a vida e a segurança pública. (SILVA, 2019).

A intervenção urbanística, neste ponto, apresenta-se como uma técnica capaz de, para além de promover melhor funcionalidade, permitir certa organização capaz de regular os fluxos, separando multidões e reafirmando a condição hegemônica de determinados grupos sociais nos espaços urbanos por eles ocupados. Destarte, a biopolítica também se apresenta como uma técnica "dos controles produzidos por tal "disfunção", e o urbanismo, na resolução das disfunções urbanas, elabora uma "patologia do espaço", e intervém no sentido de sua normalização”. (FERNANDES, 2005, p. 17). 
Se insere, neste contexto, o que Foucault (1984) chama de "medicina urbana", porquanto a preocupação da política urbana protagoniza o controle do corpo social, especialmente das "massas urbanas potencialmente sediciosas". (FERNANDES, 2005, p. 17). Isso porque, como visto, os espaços públicos, preenchidos por tecnologias biopolíticas, parecem, em um primeiro momento, fazer prevalecer o exercício da vida humana, porquanto preenchidos de portas eletrônicas, alarmes e câmeras. No entanto, conforme aponta Agamben, estes representam, em verdade, tecnologias que servem para separar os corpos que merecem viver, dos corpos inúteis: da vida nua. (AGAMBEN, 2010). Isso apenas solidifica o entendimento de que as intervenções urbanizadoras, que visam conferir uma forma à cidade, contêm, em si, um projeto de gerenciamento do urbano em sua totalidade, seja promovendo zonas de morte, seja evitando a passagem de corpos "indesejáveis" nos centros urbanos 9 .

Conforme já explicitado, esta expulsão dos centros urbanos face às classes desprivilegiadas, está representada, também, por meio de violência despendida contra os processos de retomada dos espaços públicos. De acordo com a pesquisa de Maiquel e Nielson, a expulsão dos indivíduos de determinadas ocupações significaram verdadeiras estratégias de "limpeza urbana", ou seja, "de expulsão das classes pobres para fora dos centros das grandes cidades - em direção aos chamados "cinturões" ou "bolsões" de pobreza que caracterizam as cidades do país". (NIELSON; WERMUTH, 2018, p. 615-616).

É, por isso, que os mecanismos que perpassam o campo da biopolítica podem ser identificados não somente pelo abuso e/ou pela falta de direitos e garantias, mas, também, por permearem outros campos da vida humana, como, por exemplo, a economia, justamente por marcarem a

\begin{abstract}
[...] transição de um regime da escassez de mão-de-obra - que pressupõe a produção de corpos docilizados - para um regime de excesso - que perpassa pela produção da "vida nua", ou seja, aquela vida politicamente irrelevante e que, por conta disso, pode ser impunemente violada/eliminada. [...] Nesse sentido, esquadrinhar o espaço urbano, demarcar espaços para o habitar da vida politicamente qualificada (bios) pressupõe a contínua separação da mera vida (zoé), ou seja, daquela vida indigna de ser vivida e que, por isso, revela-se como uma vida matável (homo sacer). (NIELSON; WERMUTH, 2018, p. 616).
\end{abstract}

\footnotetext{
${ }^{9}$ Gize-se, no entanto, que esta pesquisa não comporta o entendimento de que a cidade não precisa de segurança urbana, pelo contrário: se coloca, aqui, a diferença entre a segurança dos centros urbanos -que, em sua grande maioria, possuem aparatos eletrônicos e a vasta presença de policiamento- face à forma como a polícia age em locais mais periféricos, com truculência e arbitrariedade.
} 


\section{A BIOPOLITICA E OS CONTORNOS DA CIDADE: \\ UMA ANÁLISE DOS MECANISMOS DE GERENCIAMENTO A PARTIR DE MICHEL FOUCAULT}

Para Soares (2015, p. 30), a exclusão de sujeitos dos centros urbanos permeia duas formas de abordagem e intervenção no que tange ao lugar de ação da Polícia Militar. De um lado, estaria o modo de ação da classe média ou alta e, do outro, as periferias urbanas e as favelas. Esta última, por sua vez, considerar-se-ia como o território "inimigo", onde “corporações militares tendem a ensejar culturas afetas à violência, cujo eixo é a ideia de que segurança implica guerra contra o "inimigo". Não raro essa figura é projetada sobre o jovem pobre e negro".

A problematização da exclusão de sujeitos nos espaços urbanos a partir da gestão do campo biopolítico, só se torna admissível quando o Estado identifica, de acordo com Foucault, a necessidade da eliminação do perigo biológico, a fim de fortalecer outras “espécies”, condição necessária para aceitar tirar a vida de indivíduos em uma sociedade que prioriza a normalização. Para o filósofo francês, “o racismo é indispensável como condição para poder tirar a vida de alguém, para poder tirar a vida dos outros. A função assassina do Estado só pode ser assegurada, desde que o Estado funcione no modo do biopoder, pelo racismo". (FOUCAULT, 2010, p. 215).

Compreende-se, nesta medida, que, para que haja justificação política que viabilize a suspensão de direitos de determinados indivíduos, é necessário, primeiramente, que haja a fragmentação da população - que, como visto, pode ocorrer por meio da exclusão dos centros urbanos- para, enfim, estigmatizar uma parte desta, considerando-a como "inimiga". O racismo, nesta medida, opera de forma funcional, a fim de permitir esta fragmentação, porquanto, na atualidade, o racismo perpassa questões além da raça, passando e envolver, também, a classe social, a cultura e, inclusive a própria religião dos sujeitos envolvidos. É, portanto, a partir desta dinâmica, que se torna possível explicar tamanhos números de mortos devidos às ações policiais em bairros periféricos, bem como a ausência de direitos básicos naqueles locais ${ }^{10}$.

Os exemplos aqui presentados, como mortes violentas e privações de direitos fundamentais, se apresentam como consequências de mecanismos biopolíticos que permitem “a fragmentação do espaço urbano, como as periferias - territórios de exceção- que vivem uma constante violação dos direitos de cidadania". A continuidade de mecanismos biopolíticos que permitem a inserção de dispositivos que não zelam pelo "fazer viver" de 10 Para maiores informações sobre falta de saneamento básico e saúde em locais periféricos, acesse:
https://www.comissaojusticaepazdf.org.br/saneamento-basico-pobreza-saude-e-meio-ambiente-11022016/

Rev. de Direito Urbanístico, Cidade e Alteridade | e-ISSN: 2525-989X | Evento Virtual | v. 6 | n. 1 | 
todos os indivíduos, vêm a protagonizar a separação da população entre aqueles que residem em territórios "inimigos", entre eles, "a classe trabalhadora, negros e pobres - e o resto dos cidadãos". (FAZZINI, 2018, p. 472-485).

Assim, diante do aqui apresentado, verifica-se que a biopolítica e a forma como a sociedade se divide no espaço urbano caracteriza-se pela formação de territórios que permitem a exclusão e a construção do outro como não semelhante e/ou como ameaçador, permitindo, desta forma, a não observância da salvaguarda de direitos e garantias destinados a determinada localidade. Estes episódios acabam sendo facilitados pela exclusão de indivíduos dos centros urbanos, por meio de mecanismos biopolíticos que, por meio de estratégias de poderes, pautadas pelo racismo institucional, passam a regular fenômenos em massa, exercendo um poder que se aloca sobre o corpo mecânico da população, constituindo-se como elementos essenciais aptos a demarcar espaços para o habitar da vida politicamente qualificada.

\section{CONSIDERAÇÕES FINAIS}

Durante o curso desta pesquisa, foi possível identificar, em um primeiro momento, no que constitui o instituto da Biopolítica, cunhado por Foucault. Observou-se que esta designa a maneira pela qual o poder tende a se transformar, a partir do início do século XIX, com o intuito de governar os sujeitos por meio do conjunto dos problemas atinentes aos indivíduos constituídos enquanto população. A biopolítica, ocupar-se-ia, portanto, de questões amplas, que incidem sobre os processos globais, como, por exemplo, a gestão da saúde, da higiene, da sexualidade e, inclusive, da distribuição dos indivíduos nas cidades.

No que tange à distribuição das cidades, a biopolítica, conforme demonstrado, logra êxito ao instituir mecanismos que determinam locais específicos para residência de sujeitos enquanto ocupantes do espaço urbano, na medida em que estes elementos também se constituem como preocupações políticas. Ao separar quem merece usufruir dos centros urbanos, excluindo os seres "indesejáveis", a biopolítica também se apresenta como uma política populacional, capaz de regular e produzir comunidades urbanas por meio de regras de higiene, segurança e fluxos migratórios. Por decorrência, este instituto, procura, por meio destes mecanismos, dar conta de uma de suas premissas, pautadas na normalização biológica 
da espécie humana e conduziram, desde Foucault, à problemática da governamentalidade, tendo em vista os enunciados sobre a segurança e o risco.

Por fim, esta pesquisa retomou à problemática inicial, demonstrando que o racismo institucional se constitui como elemento essencial a demarcar espaços para o habitar da vida politicamente qualificada. Diante disso, constatou-se, de acordo com os aportes de Foucault, que a biopolítica se utiliza do racismo institucional para fragmentar o tecido social, de modo a estabelecer uma certa "higienização populacional", permitindo, desta forma, a criação de "zonas de morte", onde o racismo se apresenta como premissa para estabelecer o direito de matar o outro, mesmo que de forma não literal, mas por decorrência da privação de direitos e garantias dos indivíduos que se encontram inseridos naqueles locais. 


\section{REFERÊNCIAS}

AGAMBEN, Giorgio. Homo sacer: o poder soberano e a vida nua I. Trad. Henrique Burigo. Belo Horizonte: Editora UFMG, 2010.

ALANI, Natassia D'Agostin. A biopolitica e o espaço urbano:: considerações sobre o Centro de Florianópolis. Revista Rua, Campinas, v. 25, ed. 2, p. 441-467, nov. 2019. DOI https://doi.org/10.20396/rua.v25i2.8657562. Disponível em:

https://periodicos.sbu.unicamp.br/ojs/index.php/rua/article/view/8657562. Acesso em: 1 fev. 2020.

AREND, Nathan Franciel. A cidade de ambulante: cartografando o centro de Porto Alegre. 2018. 116 f. Dissertação (Mestrado). Programa de Pós-Graduação em Planejamento Urbano e Regional, Universidade Federal do Rio Grande do Sul, Porto Alegre, 2018.

ARENDT, Hannah. A Condição Humana. Rio de Janeiro: Forense Universitária.1984.

AYUB, João Paulo. Introdução à analítica do poder de Michel Foucault. São Paulo: Intermeios, 2015.

BAZZICALUPO, Laura. Bipolítica: um mapa conceitual. Tradução Luísa Rabolini. São Leopoldo: Editora Unisinos, 2017.

BITTENCOURT, Naiara Andreoli. A Biopolítica sobre a vida das mulheres e o controle jurídico brasileiro. Revista Gênero e Direito, Paraíba, v. 4, n. 3, ano 2015. Disponível em http://periodicos.ufpb.br/ojs2/index.php/ged/article/view/2596>. Acesso em: 13 jan. 2020.

FAZZINI, Lucas, Territórios de exceção: poder, espaço urbano, literatura. In: RUA [online], v. 24, ed. 2, p. 461-487 nov. 2018. Consultada no Portal Labeurb - Revista do Laboratório de Estudos Urbanos do Núcleo de Desenvolvimento da Criatividade. Disponível em:

http://www.labeurb.unicamp.br/rua/. Acesso em: 01 fev. 2020.

FERNANDES, Fernando lannes. Os discursos sobre as favelas e os limites ao direito à cidade. Cidades: Grupo de Estudos Urbanos, Presidente Prudente, p. 37-62, 1 jan/jun. 2005. Disponível em:

https://www.researchgate.net/publication/287647717_Os_discursos_sobre_as_favelas_os_os_ limites_ao_direito_a_cidade. Acesso em: 1 fev. 2020.

FINNIS, John. Natural Law and Natural Rights, OXFORD: Clarendon Press. 1980.

FOISNEU ,Luc. Pluralismo e concepção do bem em Thomas Hobbes. Porto Alegre: Linus, 2009.

FOUCAULT, Michel. Em defesa da sociedade: curso no Collège de France (1975-1976). 2. ed. São Paulo: WMF Martins Fontes, 2010.

FOUCAULT, Michel. História da sexualidade I: a vontade de saber. 22. reimpr. Rio de Janeiro: Edições Graal, 2012.

FOUCAULT, Michel. Microfísica do Poder. Rio de Janeiro, GRAAL, 1986.

FOUCAULT, Michel. Nascimento da Biopolítica. Tradução de Eduardo Brandão. São Paulo: Martins fontes, 2008.

Rev. de Direito Urbanístico, Cidade e Alteridade | e-ISSN: 2525-989X | Evento Virtual | v. 6 | n. 1 | 
FOUCAULT, Michel. Segurança, Território, População. Curso no Collége de France. São Paulo: Martins Fontes, 2008.

FOUCAULT. Michel (1984). O nascimento da medicina social. In: Microfísica do poder. Rio de Janeiro: Graal.

HOBBES, Thomas. Leviatã ou matéria, forma e poder de um estado eclesiástico e civil. São Paulo: Nova cultural, 1988.

LARA, Camila de Almeida; BUTTURI JUNIOR, Atílio. Biopolítica, Direitos Humanos e Resistências: uma análise comparativa das políticas públicas de saúde para a população LGBT de Florianópolis-SC. Trabalhos em Linguística Aplicada, Campinas, v 57, n.2, pp.645674, mai./ago, 2018. Disponível em:

https://periodicos.sbu.unicamp.br/ojs/index.php/tla/article/view/8651640/18317. Acesso em: 21 jan. 2020.

LOUREIRO, Carlos Henrique A. Urban reform and Biopolitical city. 2014. $106 \mathrm{f}$.

Dissertação (Mestrado em Filosofia) - Pontifícia Universidade Católica de São Paulo, São Paulo, 2014. Disponível em: https://tede2.pucsp.br/handle/handle/11668. Acesso em $01 \mathrm{fev}$. 2020.

NASCIMENTO, Mariangêla. Soberania, poder e biopolítica: Arendt, Foucault e Negri. Griot, Bahia, v. 6, n. 2, p. 152-169, dez. 2012. Disponível em:

http://www2.ufrb.edu.br/griot/images/vol6-

n2/11soberania_poder_e_biopolitica_arendt_foucault_e_negri_soberaniamariangela_nascime nto.pdf $>$.Acesso em: $27 \overline{\text { jan. }} 2020$.

NIELSON, Joice Graciele; WERMUTH, Maiquel Ângelo Dezordi. Os higienistas estão voltando: biopolítica, classes subalternizadas e ocupação do espaço urbano no Brasil. In: Revista de Direito da Cidade, Rio de Janeiro, v. 10, ed. 2, p. 596-619, 1 jun. 2018. DOI DOI: 10.12957/rdc.2018.30172. Disponível em: https://www.epublicacoes.uerj.br/index.php/rdc/article/view/30172. Acesso em: 1 fev. 2020.

PAESE, Celma. O Campo e a arquitetura. Arqtexto (UFRGS). Porto Alegre, v. 7, n.7, p. 50-59, 2006.

PELBART, Peter Pal. Vida Capital Ensaios de Biopolítica. São Paulo: Editora Iluminuras LTDA, 2003.

RITTER, Vivian Fetzner. O espaço e a biopolítica. Polietica. São Paulo, v. 2, n. 1, pp. $112-$ 137, 2014.

SILVA, ELIANA SOUSA. Segurança no rio:: Direito nao chegou a favelas ou periferias. Nexo, Brasil, p. 1, 30 jul. 2019. Disponível em: https://www.nexojornal.com.br/ensaio/2019/Seguran\%C3\%A7a-no-Rio-direito-n\%C3\%A3ochegou-a-favelas-e-periferias. Acesso em: 1 fev. 2020.

SOARES, Luiz Eduardo. Por que tem sido tão difícil mudar os policiais. In: A violência

Policial no Brasil e os desafios para sua superação. São Paulo: Boitempo, 2015. 